and D. George (eds.)

\title{
The Magelonidae (Annelida: Polychaeta) from the Seychelles. 2. Description of four additional species, three new to science
}

\author{
KATE MORTIMER and ANDREW S.Y. MACKIE \\ Department of Biodiversity and Systematic Biology, National Museum of Wales, Cathays Park, Cardiff CF10 3NP, Wales, \\ U.K. E-mail: Katie.mortimer@nmgw.ac.uk
}

\begin{abstract}
SUMMARY: In 2000, the National Museum of Wales mounted a marine biological expedition to the Seychelles as part of the Shoals of Capricorn programme. Following this, three new species of Magelona (M. conversa, M. falcifera and M. gemmata) were described, and published in the Proceedings of the $7^{\text {th }}$ International Polychaete Conference. In this second paper, the authors describe a further three new species (M. symmetrica, M. mahensis and M. cepiceps) and present a new record of M. pygmaea Nateewathana and Hylleberg, 1991 - previously known only from Thailand. The taxonomic affinities of the four species are discussed and a key is provided to all seven recorded from the Seychelles.
\end{abstract}

Keywords: Magelona, Magelonidae, Polychaeta, new species, Seychelles, Indian Ocean.

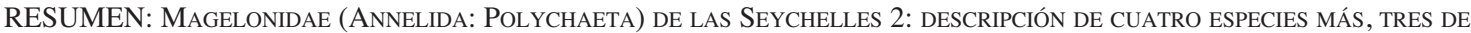
ELLAS NUEVAS PARA LA CIENCIA. - En el año 2000, dentro del programa Shoals of Capricorn, el Museo Nacional del País de Gales organizó una expedición biológica marina a las Seychelles. Tras ella, se describieron tres nuevas especies de Magelona (M. conversa, M. falcifera, y M. gemmata) que fueron publicadas en los Proceedings of the $7^{\text {th }}$ International Polychaete Conference. En este segundo trabajo, los autores describen tres nuevas especies más (M. symmetrica, M. mahensis y M. cepiceps) y citan nuevamente a M. pygmaea Nateewathana y Hylleberg, 1991 previamente sólo hallada en Tailandia. Se discuten las afinidades taxonómicas de las cuatro especies y se proporciona una clave para las siete especies citadas en las Seychelles.

Palabras clave: Magelona, Magelonidae, Polychaeta, especies nuevas, Seychelles, Océano Índico.

\section{INTRODUCTION}

In an earlier paper, Mortimer and Mackie (2003) initiated a study of the Magelonidae collected during the Seychelles marine biological expedition carried out by the National Museum of Wales in 2000, under the auspices of the Royal Geographical Society (with IBG) / Royal Society's Shoals of Capricorn programme, Western Indian Ocean 1998-2001. To date, the polychaetes of the Seychelles, in the western Indian Ocean, have received relatively little taxonomic attention. However, the biodiversity of the infaunal polychaetes and molluscs around Mahé, the main island, has been shown to be very high (Mackie et al., 2005).

Presently, there are approximately 64 recognised magelonid species. Almost all are included in the genus Magelona Müller 1858, however, two species have been described for Meredithia HernándezAlcántara and Solís-Weiss, 2000 and one for Octomagelona Aguirrezabalaga, Ceberio and Fiege, 
2001. The validity of Meredithia was questioned by Mortimer and Mackie (2003).

Twenty three Magelona species have been described from the Indian Ocean / Indo-West Pacific region: M. capensis Day, 1961 and M. cincta Ehlers, 1908 (South Africa); M. obockensis Gravier, 1906 (Red Sea); M. cornuta Wesenberg-Lund, 1949, M. puchella Mohammad, 1970 and $M$. heteropoda Mohammad, 1973 (Arabian Gulf); M. kamala, M. tinae, M. pygmaea, M. petersenae, M. methae, $M$. mickminni, M. pectinata and M.noppi Nateewathana and Hylleberg, 1991 (Thailand); M. crenulifrons and M. lenticulata Gallardo, 1968 (Viet Nam), M. japonica and M. koreana Okuda, 1937 (Korea); M. agoensis Kitamori, 1967 (Japan); M. sachalinensis Buzhinskaja, 1985 (Sakhalin Island) and M. conversa, M. falcifera and M. gemmata Mortimer and Mackie, 2003 (Seychelles).

In addition, the following North and South American species have also been recorded from this area: M. rosea Moore, 1907 (Thailand: Fauvel, 1953); M. californica Hartman, 1944, M. pitelkai Hartman, 1944, and M. longicornis Johnson, 1901 (Japan: Kitamori, 1967); M. papillicornis F. Müller, 1858 (Red Sea: Amoureux, 1983).

One Seychelles species, Magelona gemmata, was recently recorded off the island of Natuna Besar in the South China Sea (Al-Hakin and Glasby, 2004).

This second study of the Seychelles magelonids (Shoals of Capricorn publication P055) includes detailed descriptions of three new species, as well as M. pygmaea Nateewathana and Hylleberg, 1991, originally described from Thailand.

\section{MATERIALS AND METHODS}

All material was collected during the National Museum of Wales expedition to the island of Mahé in March 2000. Samples were collected for both taxonomic research and biodiversity assessments.

All samples in this paper were obtained from a series of sublittoral stations around Mahé (Fig. 1) using the modified $0.1 \mathrm{~m}^{2}$ Van Veen grabs (Station replicates designated a, b, c...) first successfully deployed in the Irish Sea in 1997 (Wilson et al., 2001) or Tjärnö dredge. Samples were sieved (0.5 $\mathrm{mm}$ mesh) and fixed in formalin, mostly stained with Rose Bengal. Specimens were subsequently preserved in $80 \%$ alcohol with $2 \%$ propylene glycol (Mackie and Oliver 1996).

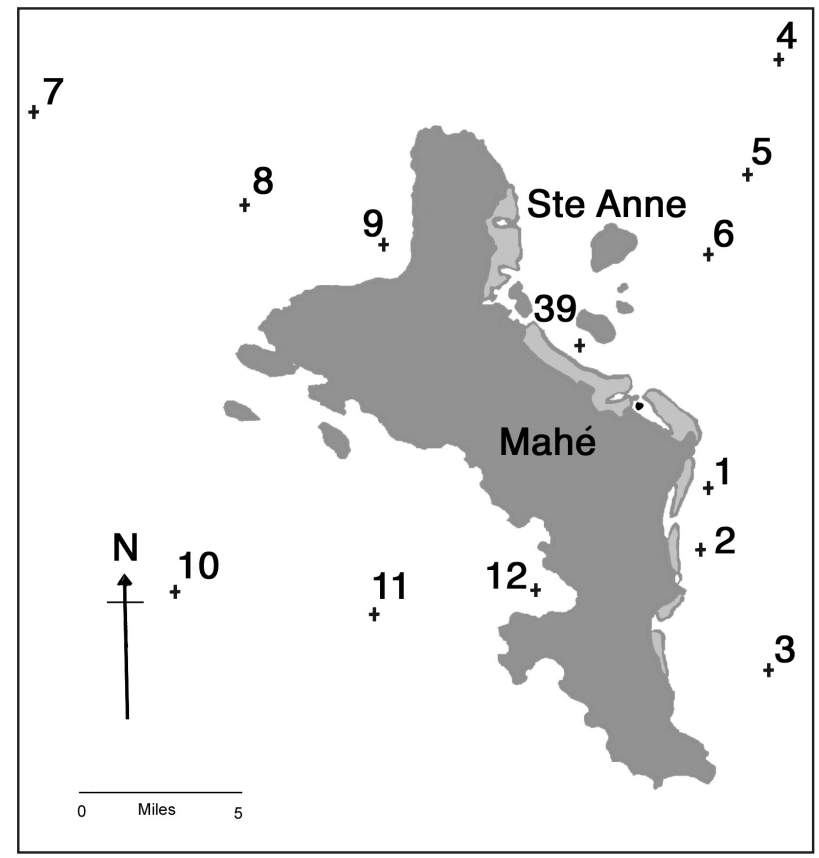

FIG. 1. - Positions of benthic sampling stations, Seychelles expedition 2000.

All drawings were made using a camera lucida attachment on a Leica MZ9.5 zoom microscope, or Nikon Labophot-2 compound microscope.

In order to keep consistency in the descriptions within this family, specimen descriptions follow the same format as those described in Mortimer and Mackie (2003). For example, specimens are herein recorded as complete (c), anterior fragments (af), posterior fragments (pf) or fragments (f). Lateral pouches on abdominal chaetigers were recorded here according to the morphologies described by Fiege et al. (2000): $\Sigma$ configuration anteriorly open pouches (often convoluted) bounded dorsally and ventrally by large cuticular flaps; C configuration - posteriorly open pouches, often inconspicuous, ventral part sometimes folded over flattening pouch against body. Parapodial structures are primarily described relative to basic polychaete terminology (e.g. postchaetal, prechaetal etc.), however, certain of the terms introduced by Jones $(1971,1978)$ are also given (e.g. dorsal medial lobe - DML, ventral medial lobe - VML) to facilitate cross-comparisons with other publications.

All type material is deposited in the National Museum of Wales (NMW), Cardiff. Paratype and non-type material of $M$. pygmaea Nateewathana and Hylleberg, 1991 was obtained from Phuket Marine Biological Center (PMBC). 

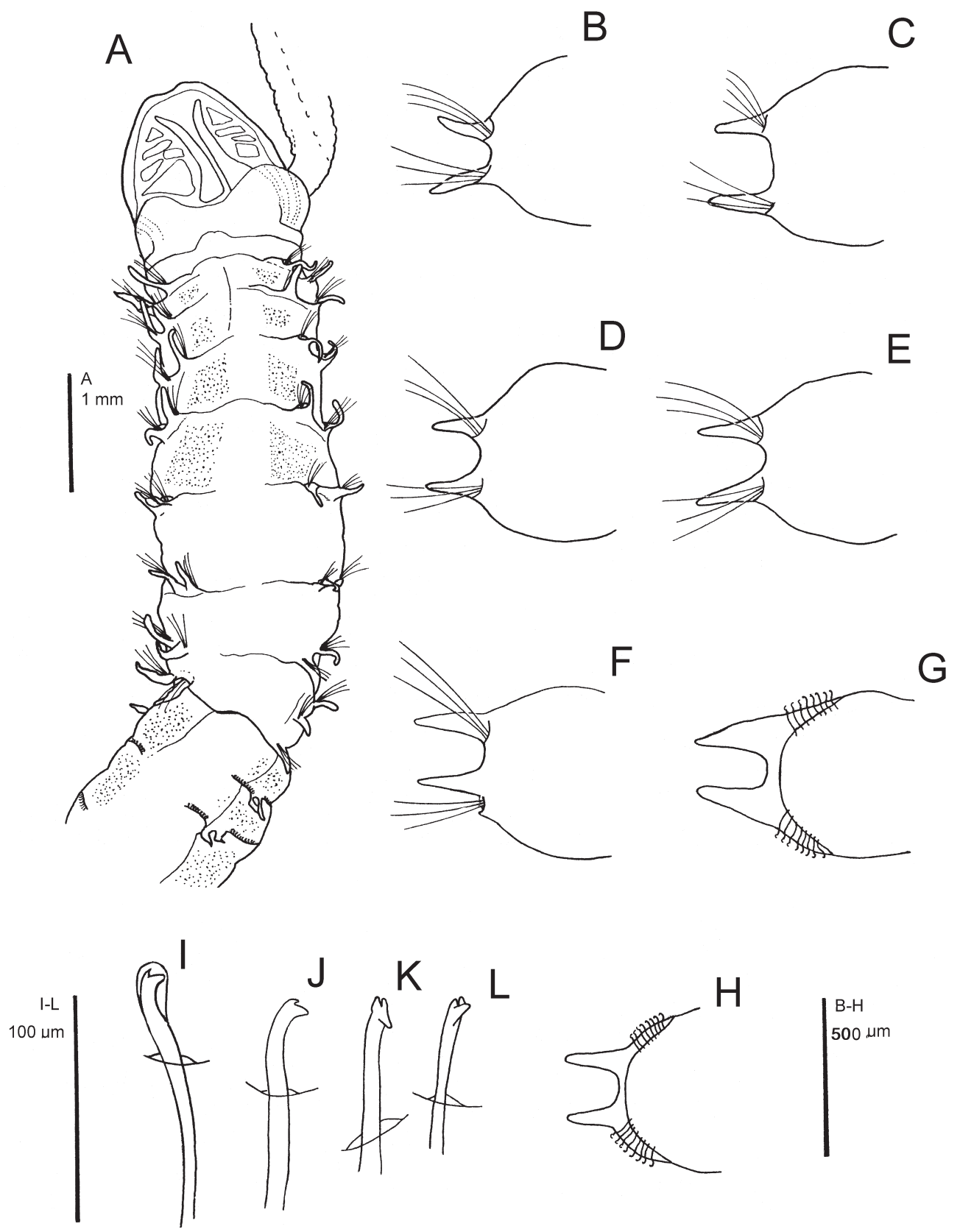

FIG. 2. - Magelona symmetrica sp. nov. (holotype, NMW.Z.2000.020.0175) A, Anterior region, dorsal view; B, Chaetiger 1, anterior view; C, Chaetiger 5, anterior view; D, Chaetiger 6, anterior view; E, Chaetiger 8, anterior view; F, Chaetiger 9, anterior view; G, Chaetiger 10, anterior view; H, Chaetiger 28, anterior view; I-L, Abdominal tridentate hooded hooks (for clarity hoods omitted from J-L).

\section{SYSTEMATIC ACCOUNT}

Family Magelonidae Cunningham and

\section{Ramage, 1888}

Genus Magelona F. Müller, 1858; emended Fiege et al. (2000)

Maea Johnston, 1865

Rhynophylla Carrington, 1865

Papillaria Sveshnikov, 1963

Meredithia Hernández-Alcántara and Solís-Weiss, 2000

\section{Magelona symmetrica $\mathrm{n}$. sp.}

(Fig. 2)

Material examined. Seychelles: E of Mahé, Stn 1c (4²1.24'S, $55^{\circ} 32.19^{\prime} \mathrm{E}$ ), fine and medium sand and coral sediment, $20 \mathrm{~m}$, holotype (NMW.Z.2000.020.0175; 1af, 3f), Van Veen 2 (VV2), 7.03 .00 .

Diagnosis. Stout species. Prostomium wider than long, subtrapezoidal, without prostomial horns. Palps robust, densely papillated. Chaetigers $1-9$ with slender, smooth-edged, triangular postchaetal lamel- 
lae. Thoracic chaetigers only with capillary chaetae. Abdominal lateral lamellae long, pointed triangular. Hooded hooks tridentate, in two facing groups (vis$a$-vis). No lateral pouches of $\Sigma$ configuration on anterior abdominal chaetigers. Posterior region unknown.

Description. A large, stout species (Fig. 2A); thorax width similar to abdomen. Holotype an anterior fragment and three median fragments; pygidium lacking. Thorax (including prostomium) $4.7 \mathrm{~mm}$ long, $1.5 \mathrm{~mm}$ maximum width, total length $12.5 \mathrm{~mm}$ for 26 chaetigers. Abdominal fragments each of nine or ten chaetigers.

Prostomium wider than long (L:W ratio 0.73), subtrapezoidal, anterior margin smooth and medially indented, prostomial horns and eyes absent; two prominent longitudinal dorsal muscular ridges, separated for entirety, anteriorly divergent. Proboscis not everted. Palps arise ventrolaterally from base of prostomium, short, reaching chaetigers 9-10 (distal tip missing?). Palps papillated almost to base (non-papillated region reaching to chaetiger 1), with 8-10 rows of papillae proximally, reducing to 6 medially and 2 distally, either side of inconspicuous ventral groove (papillae long, length decreasing only at proximal end). Both palps now detached.

Peristomium of roughly equal size to chaetiger 1 . Chaetigers 1-8 (Fig. 2B-E) similar; parapodia biramous, low triangular notopodial prechaetal ridges confluent with slender triangular postchaetal lamellae. Neuropodial postchaetal lamellae triangular with low prechaetal ridges, initially ventral in position, becoming entirely postchaetal from chaetiger 5 .

Chaetiger 9 (Fig. 2F): Notopodia similar to preceding chaetigers, but neuropodial lamellae triangular, lateral, with low inferior postchaetal ridge terminating in small triangular process. Prechaetal lamellae low ridges in both rami. All thoracic chaetae simple capillaries.

Abdominal chaetigers with sharply-pointed triangular lateral lamellae, of about equal size in both rami (Fig. 2G-H). In anterior abdomen, lamellae longer than those of thorax. Lateral lamellae do not extend postchaetally, prechaetal ridges low and indistinct. No dorsal (DML) or ventral (VML) processes on abdominal chaetigers.

Abdominal chaetae all tridentate hooded hooks (Fig. 2I-L), of similar size. Hooks in two groups, main fangs vis-á-vis. Initially about 12-14 hooks per ramus, reducing to 8-10 on median chaetigers. Paired lateral pouches ( $\Sigma$ configuration) absent on anterior abdominal segments. No $\mathrm{C}$ configuration pouches seen. Pygidium unknown.

Colour. Observations made on a preserved holotype originally stained with Rose Bengal; now cream-white in alcohol. Methyl Green staining of glandular areas rather diffuse, no intensely stained speckles. Darkest staining in mid-dorsal and midventral areas of thorax, with cream-coloured patches noticeable dorsolaterally, laterally and on ventral pads. Cream pigmentation also particularly noticeable in abdomen as intense interparapodial patches and on mid-ventral line.

Etymology. The specific name is from 'symmetros' (Gk), meaning symmetrical, and refers to the uniformity of the noto- and neuropodial lamellae in both thorax and abdomen.

Habitat. Only found in coral sand at one shallow station east of Mahé.

Remarks. Magelona symmetrica n. sp. approaches a suite of five species [M. japonica Okuda, 1937, M. koreana Okuda, 1937 (originally M. japonica var. koreana; see Jones 1971), M. cornuta Wesenberg-Lund, 1949, M. alleni Wilson, 1958 and M. equilamellae Harmelin, 1964], based on the shape of both thoracic and abdominal lamellae. Magelona symmetrica is most similar to $M$. koreana in possessing a small ventral process on the ninth neuropodium, but differs in not having prostomial horns and sub-equal abdominal lamellae. It also differs from $M$. japonica and $M$. cornuta in lacking prostomial horns. The remaining two species, M. alleni and M. equilamellae, have thoracic pigment bands that are not seen in the new species. Further, M. equilamellae has rudimentary horns and $M$. alleni has unequal abdominal lamellae.

The following species all approach M. symmetri$c a$ in having sharply triangular abdominal lamellae: M. polydentata Jones, 1963, M. variolamellata Bolívar and Lana, 1986 and an undescribed species, Magelona sp. I of Uebelacker and Jones, 1984. However, M. polydentata and Magelona sp. I both have polydentate hooded hooks and $M$. variolamellata has thoracic lamellae which reduce in size from chaetigers 1-9. 


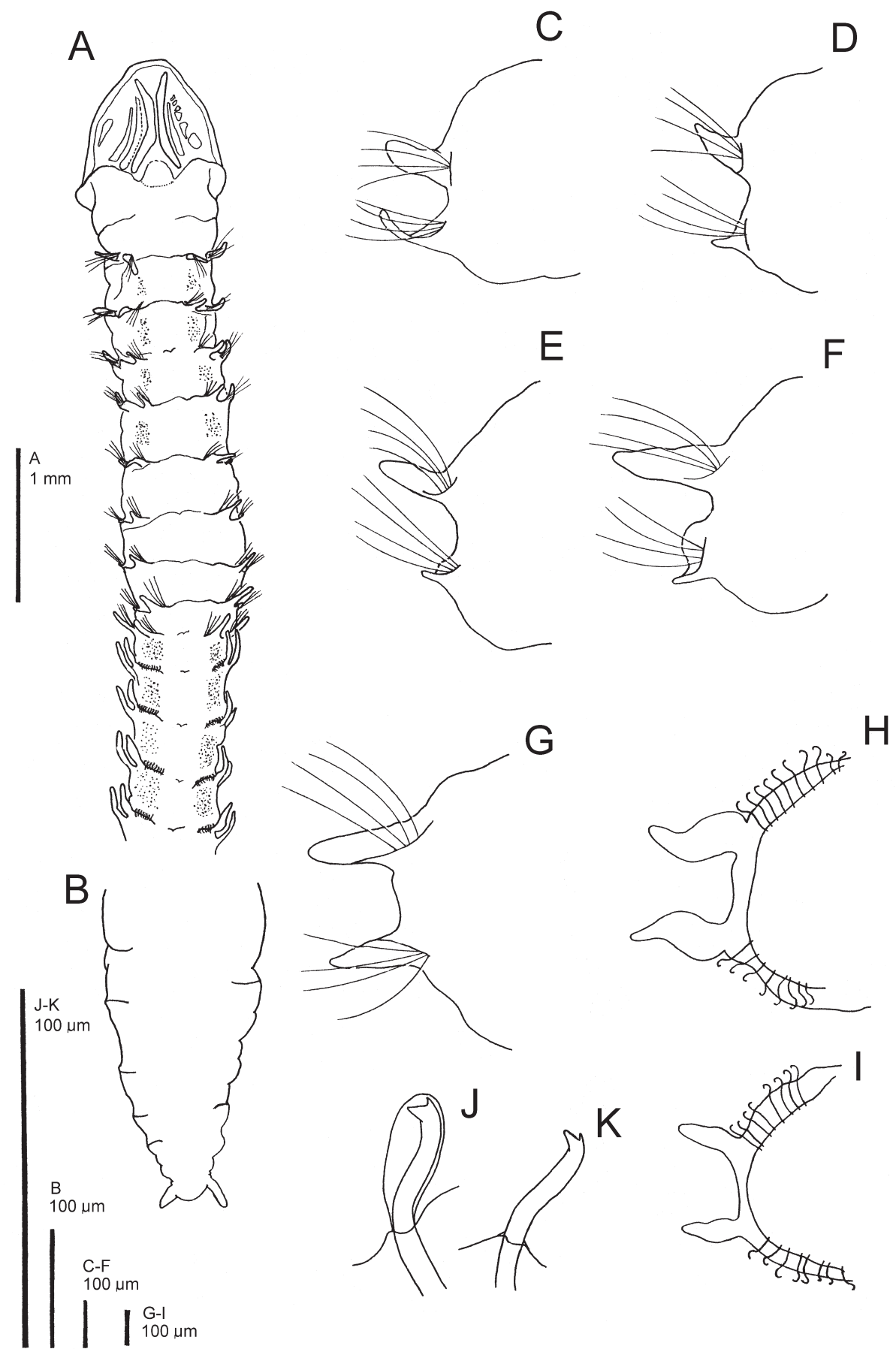

FIG. 3. - Magelona mahensis sp. nov. (A, holotype, NMW.Z.2000.020.0188; B-K, dissected paratype, Stn. 51, NMW.Z.2000.020.0191) A, Anterior region, dorsal view; B, Posterior region, dorsal view; C, Chaetiger 2, anterior view; D, Chaetiger 5, anterior view; E, Chaetiger 6, anterior view; F, Chaetiger 8, anterior view; G, Chaetiger 9, anterior view; $\mathrm{H}$, Chaetiger 10, anterior view; I, Chaetiger 50, anterior view; J, Abdominal bidentate hooded hook from chaetiger 10; K, Abdominal bidentate hooded hook from chaetiger 50 (for clarity hood omitted).

\section{Magelona mahensis n. sp.}

(Fig. 3)

Material examined. Seychelles: SE of Mahé, Stn 1a $\left(4^{\circ} 41.58^{\prime} \mathrm{S}\right.$, $\left.55^{\circ} 32.41^{\prime} \mathrm{E}\right)$, coarse sand, $22 \mathrm{~m}, 11$ paratypes (NMW.Z.2000.020.0176; 11af, 1f), Van Veen 2 (VV2), 7.03.00;

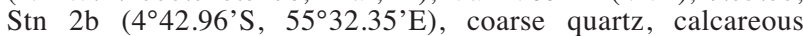
sand/gravel, 30 m, 5 paratypes (NMW.Z.2000.020.0177; 1c, 4af),

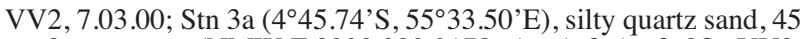
m, 2 paratypes (NMW.Z.2000.020.0178; 1c, 1af, 1 pf, 2f), VV2, 7.03.00; Stn $3 \mathrm{~b}\left(4^{\circ} 45.68^{\prime} \mathrm{S}, 5^{\circ} 33.49^{\prime} \mathrm{E}\right)$, silty quartz sand, $45 \mathrm{~m}, 4$ paratypes (NMW.Z.2000.020.0179; 1c, 3af, 2 pf), VV2, 7.03.00. SW of Mahé, Stn $11 \mathrm{c}\left(4^{\circ} 44.33^{\prime} \mathrm{S}, 55^{\circ} 24.92^{\prime} \mathrm{E}\right)$, coarse quartz sand, 48 m, 1 paratype (NMW.Z.2000.020.0180; 1af), VV2, 10.03.00; Stn $12 \mathrm{c} / \mathrm{d} / \mathrm{e}\left(\sim 4^{\circ} 44.15^{\prime} \mathrm{S}, 55^{\circ} 28.35^{\prime} \mathrm{E}\right)$, clay/mud, $27 \mathrm{~m}, 1$ paratype (NMW.Z.2000.020.0181; 1af), VV2, 10.03.00 - NW of Mahé, Stn 9a $\left(4^{\circ} 36.33^{\prime} \mathrm{S}, 55^{\circ} 24.98^{\prime} \mathrm{E}\right)$, sand, $27 \mathrm{~m}, 1$ paratype 
(NMW.Z.2000.020.0182; 1af), VV2, 9.03.00. - NE of Mahé, Stn $4 \mathrm{a}\left(4^{\circ} 32.34^{\prime} \mathrm{S}, 55^{\circ} 34.08^{\prime} \mathrm{E}\right)$, silty coarse sand, $35 \mathrm{~m}, 3$ paratypes (NMW.Z.2000.020.0183; 1c, 2af), VV2, 8.03.00; Stn 4b $\left(4^{\circ} 32.33^{\prime} \mathrm{S}, 5^{\circ} 34.14^{\prime} \mathrm{E}\right)$, silty coarse sand, $35 \mathrm{~m}, 16$ paratypes (NMW.Z.2000.020.0184; 4c, 12af, 4pf), VV2, 8.03.00; Stn 4c $\left(4^{\circ} 32.30^{\prime} \mathrm{S}, 55^{\circ} 33.96^{\prime} \mathrm{E}\right)$, silty coarse sand, $37 \mathrm{~m}, 1$ paratype (NMW.Z.2000.020.0185; 1af), VV2, 8.03.00; Stn 5a (4³4.78'S, $\left.55^{\circ} 33.17^{\prime} \mathrm{E}\right)$, medium quartz sand, $35 \mathrm{~m}, 1$ paratype (NMW.Z.2000.020.0186; 1af), VV2, 8.03.00; Stn 39a ( $4^{\circ} 38^{\prime} \mathrm{S}$, $\left.55^{\circ} 30^{\prime} \mathrm{E}\right)$, coarse coralline sand and fine sand, $11 \mathrm{~m} 1$ paratype (NMW.Z.2000.020.0187; 1 af), VV2, 20.03.00; Stn 48a (4³7.25'S, $55^{\circ} 32.24^{\prime} \mathrm{E}$ ), medium coarse coralline sand, $22 \mathrm{~m}$, holotype (NMW.Z.2000.020.0188; c), 4 paratypes (NMW.Z.2000.020.0189; 1c, 3af), VV2, 23.03.00; Stn 49 (between $4^{\circ} 37.27^{\prime} \mathrm{S}, 55^{\circ} 32.24^{\prime} \mathrm{E}$ and $4^{\circ} 37.18^{\prime} \mathrm{S}, 55^{\circ} 32.18^{\prime}$ 'E), medium-coarse coralline sand, $24 \mathrm{~m}, 4$ paratypes (NMW.Z.2000.020.0190; 4af), Tjärnö dredge, 23.03.00; Stn $51\left(4^{\circ} 36.52^{\prime} \mathrm{S}, 55^{\circ} 33.63\right.$ 'E), medium/coarse coralline sand, 34 $\mathrm{m}$, dissected paratype (NMW.Z.2000.020.0191; c), 25 paratypes (NMW.Z.2000.020.0192; 6c, 19af, 3pf, 2f), VV2, 23.03.00; Stn 52

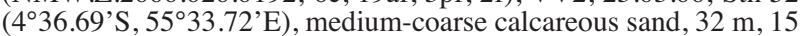
paratypes (NMW.Z.2000.020.0193; 4c, 11af, f), VV4, 23.03.00.

Diagnosis. Long, moderately slender species. Prostomium longer than wide, rounded subtriangular, without prostomial horns. Notopodia of chaetigers 19 with smooth-edged triangular postchaetal lamellae. Neuropodial lamellae slender cirriform, decreasing in size from chaetigers 4-8 to form small ventral process. Neuropodial lamellae of chaetiger 9 long, similar to notopodial. Thoracic chaetigers only with capillary chaetae. Abdominal lateral lamellae slender foliaceous. Hooded hooks bidentate, in two groups, vis-á-vis. Lateral pouches of ' $\mathrm{C}$ ' configuration on posterior abdominal chaetigers. Pygidium with pair of short lateral anal cirri.

Description. Moderately slender species; thorax wider and more dorsolaterally compressed than abdomen, with marked differences between the two regions, especially in larger specimens. Holotype entire, thorax (including prostomium) $3.1 \mathrm{~mm}$ long, $0.7 \mathrm{~mm}$ maximum width, total length $29 \mathrm{~mm}$ for 73 chaetigers. Entire paratypes (20) 14-33 mm with 5178 chaetigers.

Prostomium longer than wide (L:W ratio 1.41.5), subtriangular, anterior margin smooth and straight, prostomial horns and eyes absent; two prominent longitudinal dorsal muscular ridges, quite separated for entirety and diverging at ends, inconspicuous pair abutting inners (Fig. 3A). Proboscis a large heart-shaped sac, with conspicuous longitudinal ridges inferiorly and less conspicuously on superior surface (NMW.Z.2000.020.0177 \& 0184). Palps arising ventrolaterally from base of prostomium, short, reaching chaetigers 9-10; papillated almost to base (non-papillated region reaching to chaetiger 1). Palps with 6 rows of long papillae proximally, reducing to 1 distally, either side of inconspicuous ventral groove (papillae long, length decreasing only at proximal end).

Peristomium of roughly equal size to chaetiger 1 . Notopodia of chaetigers 1-8 similar (Fig. 3C-F); low triangular prechaetal lamellae confluent with postchaetal lamellae. Postchaetal lamellae slender, somewhat triangular, becoming slightly longer and broader toward chaetiger 8 . Ventral neuropodial lamellae slender cirriform, reducing to small digitiform ventral processes on chaetigers 4-8. Postchaetal lamellae initially low, ridge-like, becoming larger and rounder by chaetiger 8, prechaetal lamellae low.

Chaetiger 9 (Fig. 3G): Notopodia and neuropodia with low triangular prechaetal lamellae, postchaetal lamellae slender subtriangular, of similar size. All thoracic chaetae simple capillaries.

Abdominal chaetigers with slender foliaceous lateral lamellae, initially longer than those of preceding thoracic chaetigers. Lamellae basally constricted, of about equal size in both rami (Fig. 3H), becoming narrower and more lanceolate (Fig. 3I) towards posterior. Lateral lamellae do not extend pre- or postchaetally. No processes (DML and VML) on abdominal chaetigers.

Abdominal chaetae all bidentate hooded hooks (Fig. 3J-K), of similar size. Hooks in two groups, main fangs vis-á-vis. Initially about 10-12 hooks per ramus, decreasing to 4-6 on median and 3-4 on posterior chaetigers.

Paired lateral pouches ( $\Sigma$ configuration) absent on anterior abdominal segments. Unpaired lateral pouches (' $\mathrm{C}$ ' configuration) found posteriorly. These pouches often more or less folded, with thicker cuticle on edges of fold and thinner cuticle inside. Edges of fold can be abutting or overlapping. On holotype, pouches present on chaetigers $38 \mathrm{R}, 40 \mathrm{~L}, 42 \mathrm{R}, 44 \mathrm{~L}$, 45R, 48L, 50R, 52L, 54R, 56L, 58R, 60L, 62R, 64R.

Pygidium small, truncate, with two short lanceolate lateral anal cirri (Fig. 3B).

Colour. No living animals observed, all but 2 grab samples (Stn 4c and 48a) originally stained with Rose Bengal; cream-white in alcohol. Methyl Green staining evident dorsally as light speckles on posterolateral parts of prostomium, the peristomium and chaetigers 1-3. Chaetigers 4-7 densely speckled, becoming lighter on chaetiger 8 and absent on chaetiger 9. Non-staining cream-coloured longitudinal strips present dorsolaterally on chaetigers 1-4 and 8 , small cream patches on chaetiger 7 . On ven- 
ter, stained speckles sparse on chaetiger 1 , light on chaetigers 2 and 8 , increasing in density over chaetigers 3-5 and reaching a maximum on chaetigers 6 and 7. Staining of glandular areas particularly noticeable on abdominal chaetigers as intense interparapodial patches.

Etymology. The specific name refers to the type locality off the island of Mahé.

Habitat. Found at 13 stations (Stn 1, 2, 3, 4, 5, 9, $11,12,39,48,49,51,52)$, all around the island of Mahé, at depths of 11-48 m, in mud/clay, silty sand, medium coarse sand and coarse sand.

Remarks. Magelona mahensis n. sp. resembles three species; M. capax Hartman, 1965, M. variolamellata Bolívar and Lana, 1986, and an undescribed species Magelona sp. I of Uebelacker and Jones, 1984 in exhibiting a reduction in the size of the thoracic neuropodial lamellae. Magelona capax differs in having a cape-like prostomium with horns, and dorsal processes on thoracic chaetigers. The thoracic lamellae of $M$. variolamellata reduce from chaetiger 1 to 9 , whereas those of $M$. mahensis only reduce from chaetiger 4 to 8 , and $M$. variolamellata has tridentate hooks. Magelona sp. I differs markedly in having polydentate hooded hooks.

Pouches such as those seen on M. mahensis more or less folded, with thicker cuticle on edges of the fold and thinner cuticle inside - were previously also mentioned in Mortimer and Mackie (2003: 164). Fiege et al. (2000: 217) note that, for $C$ configuration pouches, "Their size and degree of protrusion is variable ..." however, the folded ' $\mathrm{C}$ ' form could be indicative of more variation than acknowledged by either the $\Sigma$ or $\mathrm{C}$ configuration, and there could possibly be intermediates between the two. More detailed examination of intra- and inter-specific variation in pouch structure is required to resolve this. The exact function of these pouches has been much discussed (Jones, 1963, 1968; McIntosh, 1878, 1911; Fiege et al., 2000), however, nothing is proven. In situ observations on living animals may ultimately prove fruitful.

\section{Magelona cepiceps n. sp.} (Fig. 4)

Material examined. Seychelles: SE of Mahé, Stn 3a (4²5.74'S, $\left.55^{\circ} 33.50^{\prime} \mathrm{E}\right)$, silty quartz sand, $45 \mathrm{~m}$, paratype (NMW.Z.2000.020.0208; 1af), VV2, 7.03.00 - NE of Mahé, Stn $50\left(4^{\circ} 37.71^{\prime} \mathrm{S}, 55^{\circ} 33.4^{\prime} \mathrm{E}\right)$, medium-coarse coralline sand, $33 \mathrm{~m}$, holotype NMW.Z.2000.020.0209; 1af, 1f), VV2, 23.3.00.

Diagnosis. Moderately stout species. Prostomium as long as wide, rounded, with rudimentary prostomial horns. Notopodia of chaetigers 1-8 with smooth-edged rounded subrectangular postchaetal lamellae and single digitiform dorsal processes. Neuropodial lamellae ventral, slender bluntly digitiform, decreasing very gradually in size from chaetiger 1 to 8 . Notopodial lamellae of chaetiger 9 rounded with single digitifor; neuropodial postchaetal lamellae, rounded triangular, with small ventral process. Thoracic chaetigers only with capillary chaetae. Abdominal lateral lamellae rounded spatulate, basally constricted, continuing postchaetally. Hooded hooks tridentate, in 2 groups, vis-á-vis.

Description. Moderately stout species; thorax wider than abdomen (Fig. 4A), constricted at chaetiger 9 . Both specimens posteriorly incomplete, larger specimen, holotype; thorax (including prostomium) $3.0 \mathrm{~mm}$ long, $1.1 \mathrm{~mm}$ maximum width, total length $7.5 \mathrm{~mm}$ for 23 chaetigers. Paratype smaller; thorax (including prostomium) $2.0 \mathrm{~mm}$ long, $0.6 \mathrm{~mm}$ wide, total length $10 \mathrm{~mm}$ for 32 chaetigers.

Prostomium as wide as long (L:W ratio 0.971.00 ), rounded, somewhat onion-shaped, anterior margin smooth and straight or slightly rounded with rudimentary prostomial horns, eyes absent; four prominent longitudinal dorsal muscular ridges, inner pair diverging at both ends and outers abutting inners (Fig. 4A). Proboscis an oval-shaped sac (paratype), with conspicuous longitudinal ridges inferiorly and less conspicuously on superior surface. Palps arising ventrolaterally from base of prostomium, short, reaching chaetigers 9-10; papillated almost to base (non-papillated region reaching to chaetiger 1). Palps, heavily papillated with 8 rows of long papillae (length decreasing only at proximal end) proximally, decreasing to 2 towards distal region, either side of inconspicuous ventral groove (on holotype right hand palp retained, distal tip missing?).

Peristomium of roughly equal size to chaetiger 1 . Notopodia of chaetigers 1-8 similar, with subrectangular postchaetal lamellae gradually increasing in size from chaetiger 4 onward (Fig. 4B-G); rounded lateral margins sometimes slightly pointed. Prechaetal lamellae triangular, inferiorly confluent with postchaetal lamellae; superiorly both pre- and 

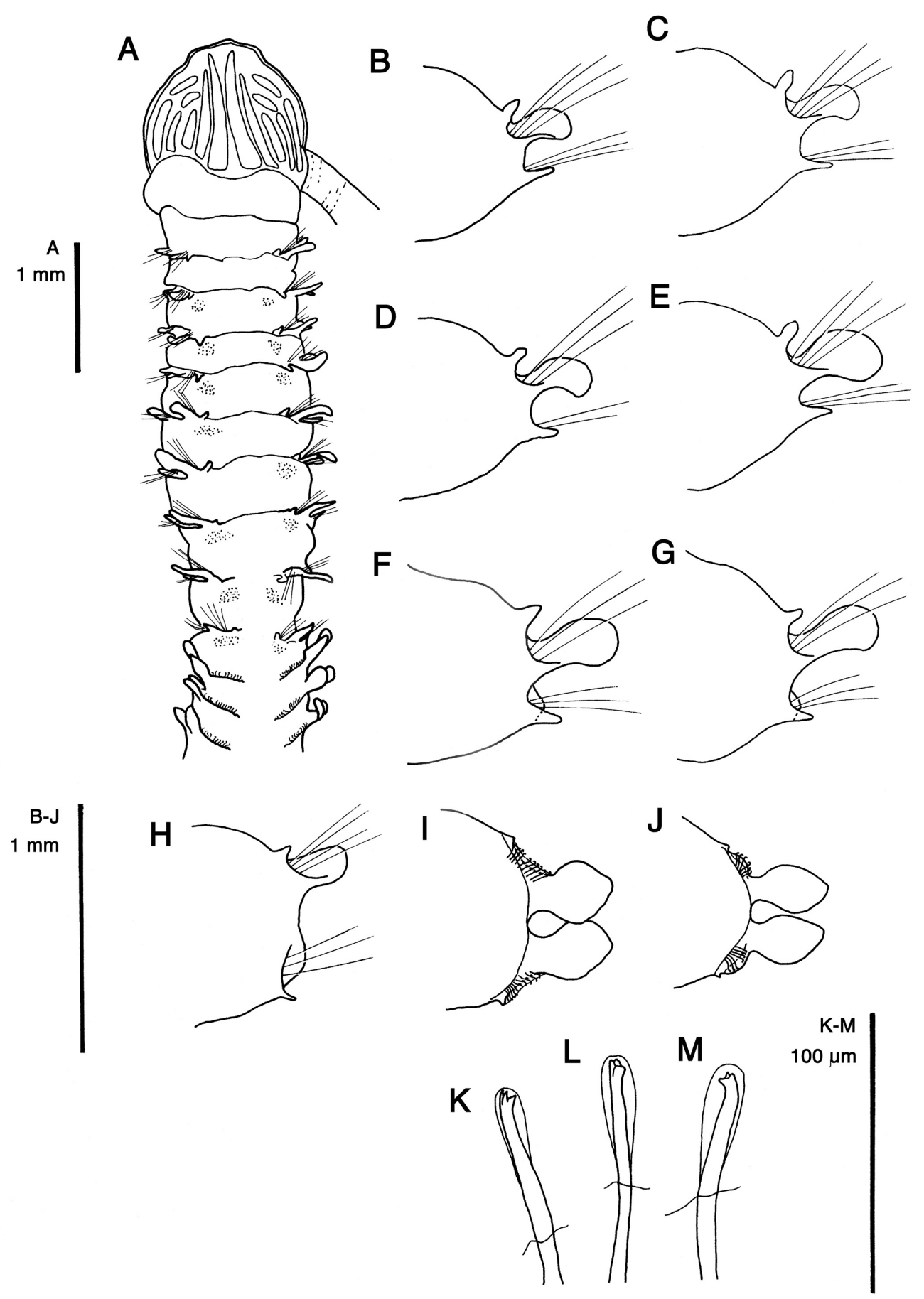

FIG. 4. - Magelona cepiceps sp. nov. (holotype, NMW.Z.2000.020.0208) A, Anterior region, dorsal view; B, Chaetiger 1, anterior view; C, Chaetiger 2, anterior view; D, Chaetiger 3, anterior view; E, Chaetiger 5, anterior view; F, Chaetiger 7, anterior view; G, Chaetiger 8 , anterior view; H, Chaetiger 9, anterior view; I, Chaetiger 10; J, Chaetiger 22, anterior view; K-M, Tridentate abdominal hooded hooks.

postchaetal lamellae fused to bases of single digitiform processes (DML). Superior processes become broader towards chaetiger 6 , then more slender again on chaetigers 8 and 9 . Neuropodial lamellae ventral; slender, bluntly digitiform, decreasing very gradually in size from chaetiger 1 to 8 . Postchaetal lamellae initially low and indistinct, becoming rounded triangular and more prominent by chaetiger 5; prechaetal lamellae low throughout.

Chaetiger 9 (Fig. 4H): Notopodial lamellae shorter and more rounded than on preceding chaetigers, though shape variable, superior processes more slender than on chaetiger 8 . Neuropodial lamellae lateral, broad-based rounded triangular, 
fused inferiorly to short slender digitiform process. All thoracic chaetae simple capillaries.

Abdominal chaetigers (Fig. 4I-J) with round spatulate lateral lamellae, basally constricted, of equal size in both rami, becoming more pointed towards median region. Lateral lamellae extend postchaetally in anterior abdomen but by median chaetigers this structure is reduced; postchaetal part less conspicuous in smaller specimen. Short triangular processes (DML and VML) evident on abdominal chaetigers.

Abdominal chaetae (Fig. 4K-M) all tridentate hooded hooks, of similar size. Hooks in two groups, main fangs vis-á-vis. Initially about 12 hooks per ramus, decreasing to $4-5$ by chaetiger 32 . Paired lateral pouches ( $\Sigma$ configuration) absent on anterior abdominal segments, C configuration absent on anterior and median chaetigers. Posterior region unknown.

Colour. No living animals observed, both specimens originally stained with Rose Bengal; creamwhite in alcohol. Methyl Green stained speckles sparse on lateral prostomial areas, dorsally and ventrally. Thorax generally covered with stained speckles, heaviest staining on chaetigers 3-5. Dorsally, speckles less at anterior of each segment and in mid-dorsal line. Ventrally, staining absent on the two longitudinal lateral lines that bound the paired ventral pads; chaetiger 9 with single small trapezoidal pad. White glandular inclusions in centre of each pad on chaetigers 3-8. No stained speckles in abdomen; white glandular patches in interparapodial areas.

Etymology. The specific name is from 'cepa' (L.), onion, and 'ceps' (L.), headed, referring to the outline shape of the prostomium.

Habitat. Found at two sandy stations $(33-45 \mathrm{~m}$ depth) off the east coast of Mahé.

Remarks. Including M. cepiceps $\mathrm{n}$. sp., there are 12 species of Magelona that share the possession of rounded subrectangular thoracic notopodial lamellae with dorsal processes (DML) and ventral neuropodial processes. The other 11 are $M$. pacifica Monro, 1933; M. capensis Day, 1961; M. crenuliformis Gallardo, 1968; M. lenticulata Gallardo, 1968; M. berkeleyi Jones, 1971; M. tehuanensis Hernández-Alcántara and Solís-Weiss, 2000; M. gemmata Mortimer and Mackie, 2003, and 4 unnamed species Magelona spp. G, J, K and L of Uebelacker and Jones, 1984. In overall morphology, $M$. cepiceps appears closest to $M$. berkeleyi and Magelona sp. J.

Magelona pacifica, M. crenuliformis, M. tehuanensis, M. gemmata, and Magelona spp. G, K and L can be readily distinguished from the new species in having well-developed frontal horns, while also lacking superior processes on chaetiger 9. Frontal horns are less conspicuous on $M$. capensis and $M$. berkeleyi, but they also lack dorsal processes on chaetiger 9 . The remaining two species, M. lenticulata and Magelona sp. J do possess dorsal processes on chaetiger 9, however both have frontal horns, prostomia with crenulated anterior margins and there are differences in the form of certain neuropodial postchaetal lamellae.

\section{Magelona pygmaea Nateewathana and} Hylleberg, 1991 (Fig. 5)

Material examined. Thailand: Phuket Island, Kamala Bay, fine sand, $10 \mathrm{~m}, 1$ paratype (PMBC 4220); Patong Beach, 20-40 m, 5 specimens (PMBC 4234); Bang Tao Bay, 10 m, 5 specimens (PMBC 4227), 4 specimens (PMBC 4241). - Seychelles: SE of Mahé, Stn 3a $\left(4^{\circ} 45.74^{\prime} \mathrm{S}, 5^{\circ} 33.50^{\prime} \mathrm{E}\right)$, silty quartz sand, $45 \mathrm{~m}, 18$ specimens (NMW.Z.2000.020.0194; 2c, 16af), VV2, 07.03.00. - SW of Mahé, Stn 10a $\left(4^{\circ} 44.05^{\prime} \mathrm{S}, 5^{\circ} 20.54^{\prime} \mathrm{E}\right)$, muddy sand, $55 \mathrm{~m}, 8$ specimens (NMW.Z.2000.020.0195; 8af), VV2, 10.03.00; Stn 10b (444.06'S, $55^{\circ} 20.48^{\prime} \mathrm{E}$ ), muddy sand, $57 \mathrm{~m}, 6$ specimens (NMW.Z.2000. 020.0196, 1 dissected complete specimen; NMW.Z.2000.020.0197,

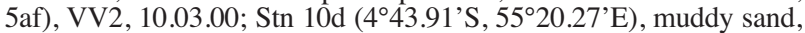
$56 \mathrm{~m}, 13$ specimens (NMW.Z.2000.020.0198; 1c, 12af), VV2, 10.03.00; Stn $11 \mathrm{c}\left(4^{\circ} 44.33^{\prime} \mathrm{S}, 5^{\circ} 24.92^{\prime} \mathrm{E}\right)$, coarse quartz sand, $48 \mathrm{~m}$, 17 specimens (NMW.Z.2000.020.0199; 2c, 15af), VV2, 10.03.00; Stn $12 \mathrm{a}\left(4^{\circ} 44.14^{\prime} \mathrm{S}, 5^{\circ} 28.30^{\prime} \mathrm{E}\right)$, muddy clay, $28 \mathrm{~m}, 2$ specimens (NMW.Z.2000.020.0200; 2af), VV2, 10.03.00; Stn 12b (444.16'S, 55²8.32'E), muddy clay, 27 m, 9 specimens (NMW.Z.2000. 020.0201, 1 specimen, largest entire specimen; NMW.Z.2000.020. 0202, 1 dissected af; NMW.Z.2000.020.0203; 1c, 6af), VV2, 10.03.00; Stn $12 \mathrm{c} / \mathrm{d} / \mathrm{e}\left(\sim 4^{\circ} 44.15^{\prime} \mathrm{S}, 5^{\circ} 28.35^{\prime} \mathrm{E}\right)$, clay/mud, $27 \mathrm{~m}, 19$ specimens (NMW.Z.2000.020.0204; 2c, 17af), VV2, 10.03.00. -

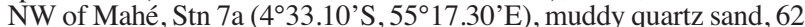
m, 10 specimens (NMW.Z.2000.020.0205; 10af), VV2,09.03.00; Stn $7 \mathrm{~b}\left(4^{\circ} 33.01^{\prime} \mathrm{S}, 55^{\circ} 17.40^{\prime} \mathrm{E}\right)$, muddy quartz sand, $63 \mathrm{~m}, 1$ specimen (NMW.Z.2000.020.0206; 1af), VV2, 09.03.00; Stn 9d (4³6.11'S, $55^{\circ} 25.03^{\prime} \mathrm{E}$ ), sand, 29 m, 1 specimen (NMW.Z.2000.020.0207; 1c), VV2, 09.03.00.

Diagnosis. Small, slender species. Prostomium wider than long, rounded triangular to subtrapezoidal, without prostomial horns. Notopodia of chaetigers 1-9 with smooth-edged triangular postchaetal lamellae. Neuropodial lamellae rounded triangular. Thoracic chaetigers only with capillary chaetae. Abdominal lateral lamellae sublanceolate. Hooded hooks tridentate, in 2 groups, vis-á-vis. No lateral pouches on abdomen. Pygidium with lateral pair of cirriform anal cirri. 

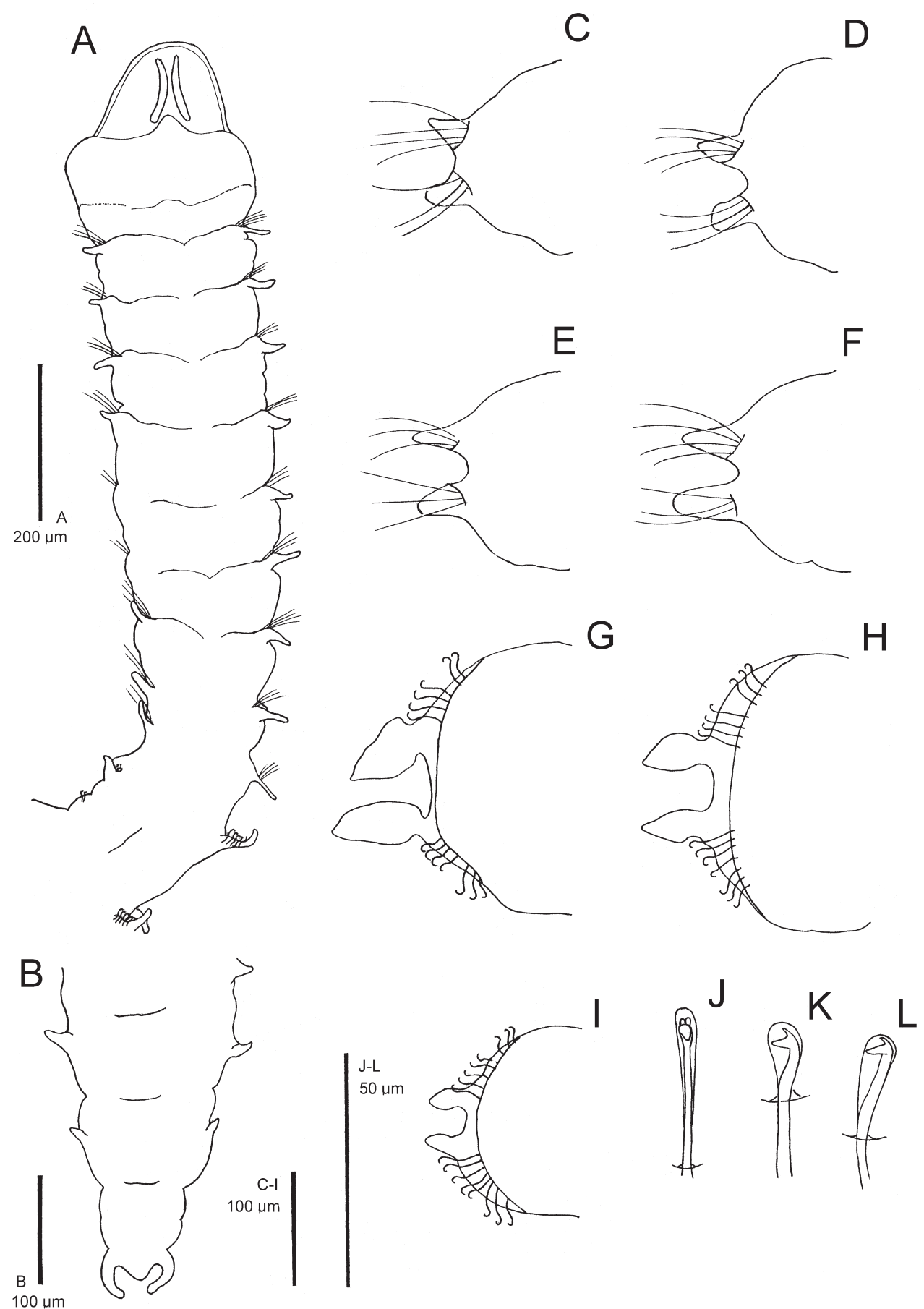

FIG. 5. - Magelona pygmaea (A-B, dissected specimen, Stn. 10b, NMW.Z.2000.020.0196; C-L, dissected specimen, Stn. 12b, NMW .Z.2000.020.0203) A, Anterior region, dorsal view; B, Posterior region, dorsal view; C, Chaetiger 1, anterior view; D, Chaetiger 4, anterior view; E, Chaetiger 8, anterior view; F, Chaetiger 9, anterior view; G, Chaetiger 12, anterior view; H, Chaetiger 20, anterior view; I, Chaetiger 45, anterior view; J-L, Tridentate abdominal hooded hooks.

Description. Small, slender species (Fig. 5A); thorax of similar width to abdomen. Largest entire Seychelles specimen ovigerous, with thorax (including prostomium) $1 \mathrm{~mm}$ long, $0.2 \mathrm{~mm}$ maximum width, total length $8.0 \mathrm{~mm}$ for 43 chaetigers. Other entire specimens (9) $3.2-7.0 \mathrm{~mm}$, for $27-48$ chaetigers. Phuket paratype $0.2 \mathrm{~mm}$ wide, $6.0 \mathrm{~mm}$ for 52 chaetigers.

Prostomium wider than long (L:W ratio 0.60.79 ), rounded triangular to subtrapezoidal, anterior 
margin smooth, prostomial horns and eyes absent; two prominent longitudinal dorsal muscular ridges, separated, diverging at both ends. Palps arising ventrolaterally from base of prostomium, long, reaching chaetigers 13-35 (usually to about chaetiger 15). Palps with non-papillated region reaching to chaetiger 2 , and 1 row of papillae on either side of inconspicuous ventral groove.

Peristomium of roughly equal size to chaetiger 1. Chaetigers 1-8 similar (Fig. 5C-E); parapodia biramous with indistinct prechaetal ridges and short triangular postchaetal lamellae. Notopodial lamellae generally more pointed and slender than ventrals, becoming broader and longer towards chaetiger 8 . Neuropodial lamellae rounded triangular, also increasing in size toward chaetiger 8 .

Chaetiger 9: similar to preceding chaetigers, lamellae slightly broader and longer (Fig. 5F). All thoracic chaetae simple capillaries.

Abdominal chaetigers with sublanceolate lateral lamellae, of about equal size in both rami, basally constricted (Fig. 5G-I). Lateral lamellae do not extend postchaetally or prechaetally, inferior and superior processes (VML and DML) absent.

Abdominal chaetae all tridentate hooded hooks (Fig. 5J-L), of similar size. Hooks in two groups, main fangs vis-á-vis. Anteriorly about 6 hooks per ramus, 6-7 on median and 6-8 on posterior chaetigers. Paired lateral pouches absent on abdominal segments. Pygidium with 2 slender anal cirri (Fig. 5B).

Colour. Observations made on preserved Seychelles specimens originally stained with Rose Bengal; cream-white in alcohol. On largest complete Seychelles specimen dorsal staining with Methyl Green evident posterolaterally on prostomium and on chaetigers 2-8, strongest on chaetiger 4. Ventral staining on chaetigers 2-9, strongest on 4-6. Interparapodial regions of anterior abdomen and posteriormost 9 chaetigers with densely stained speckles. Other Seychelles material similar, but thoracic staining variable in intensity and occurrence; prostomium often unstained. The Thai paratype shows no prostomial staining and only light staining on the thorax, particularly toward the posterior half. Lateral abdominal staining is present anteriorly. The Thai non-type material (PMBC 4227 and 4241) generally shows a similar staining pattern and a larger specimen also has some prostomial staining. The remaining material (PMBC 4234) also conforms in having predomi- nantly posterior thorax staining, however, in the abdomen there is additional staining (dense speckles) occurring as narrow dorsal and ventral transverse bands just behind the parapodia, and along a mid-ventral line.

Habitat. Found at six stations (Stn 3, 7, 9,10, 11 and 12), off the southeast and west coasts of Mahé, at depths of between $27-57 \mathrm{~m}$, in muddy sands/clays to coarse sands. The Thai type and non-type material all comes from fine sand $(10-30 \mathrm{~m})$ off the west coast of Phuket (Nateewathana and Hylleberg, 1991; Hylleberg and Nateewathana, 1991).

Remarks. Magelona pygmaea is a member of a ' $M$. papillicornis' group based on the shape and arrangement of the thoracic lamellae. There are five clear members of this group: M. papillicornis $\mathrm{F}$. Müller, 1858, M. californica Hartman, 1944, M. minuta Eliason, 1962, M. pettiboneae Jones, 1963 and M. pygmaea. Magelona pygmaea differs from all of these in possessing tridentate and not bidentate hooded hooks.

The description presented above from Seychelles material agrees well with the original one from Thailand. The small size of this species and a degree of variation in the prostomial shape (some prostomia are more rounded than originally figured) and thoracic postchaetal lamellae (on some specimens the lamellae are less pointed than originally figured) make any separation of material between the two locations difficult. Nevertheless, some of the Thai non-type material appeared to have both bi- and tridentate hooks and one lot (PMBC 4234) showed additional abdominal staining using Methyl Green. The significance of these observations is unclear at present, though a larger investigation of morphological variability within $M$. pygmaea from the type locality would be useful. Magelona pygmaea was the most widely distributed (Hylleberg and Nateewathana, 1991) of the 8 species described by Nateewathana and Hylleberg (1991).

Hylleberg and Nateewathana (1991) indicated that M. pygmaea was more abundant during a period when the silt-clay content of the sediments was reduced from $25 \%$ to $5 \%$. In the Seychelles Magelona pygmaea was present in sediments with $0.17-43.26 \%$ siltclay. The number of specimens per $0.1 \mathrm{~m}^{2}$ grab was relatively low (0-18 individuals) and there was a high degree of intra-station variability. No preference for low silt-clay sediments was found. 


\section{DISCUSSION}

The recent description of Magelona magnahamata Aguado and San Martín, 2003 agrees well with the undescribed Magelona sp. C of Uebelacker and Jones, 1984 and again raises the question of where generic delineations in the Magelonidae lie. Aguado and San Martín placed their species in Magelona, as they felt that it differed from the diagnostic characters of the type species of the genus, Meredithia spinifera, in not possessing frontal horns (Aguado, pers. comm.) - even though it possessed enlarged abdominal chaetae, a feature shared by both species attributed to Meredithia HernándezAlcántara and Solís-Weiss, 2000.

Mortimer and Mackie (2003) placed their M.falcifera in Magelona, rather than Meredithia, arguing that the significance of enlarged hooks required more rigorous study (e.g, through cladistic analyses) before Meredithia could be accepted. Magelona falcifera, as M. magnahamata, also lacks frontal horns.

Including the three new species described herein, there are now 26 species of Magelona described from the Indian Ocean / Indo-West Pacific region. This equates to almost $39 \%$ of the world total. The Magelonidae of the region seem particularly diverse, since there is relatively little evidence of widespread species distributions. In their study in the Natuna Islands (South China Sea), Al-Hakim and Glasby (2004) recorded three species originally known from three quite disparate locations: $M$. cincta from South Africa, M. crenuliformis from Viet Nam and M. gemmata from the Seychelles. Conversely, of the 10 species Nateewathana and Hylleberg (1991) recorded from Phuket (Thailand), 8 were new to science and only two known from other areas: $M$. cincta and $M$. crenuliformis. Similarly, of the 7 species now recognised from the Seychelles, 6 were new and only $M$. pygmaea (from Phuket) was previously known.

\section{Key to adult Magelona in Seychelles waters}

1. Prostomium with conspicuous, well-delineated frontal horns ............. M. gemmata

- Prostomium with no distinct horns . . . . . . . 2

2. Thoracic notopodia with dorsal processes ...3

- Dorsal processes lacking............. 4

3. Anterior abdomen with lateral pouches; chaetiger 9 with modified chaetae M. conversa

- No anterior pouches; chaetiger 9 capillary . .M. cepiceps
4. Anterior abdomen with greatly enlarged recurved hooded hooks ......... M. falcifera

- No enlarged hooks .................. 5

5. Thoracic notopodial postchaetal lamellae larger than neuropodial ones; neuropodial lobes reduced in size in mid-thorax ....M. mahensis

- All thoracic postchaetal lamellae of both rami similar in size and shape ..........6 6

6. Postchaetal lamellae in thorax and abdomen long, sharply triangular; large, stout species ................. symmetrica

- Thoracic postchaetal lamellae short, triangular; abdominal lamellae lanceolate, basally constricted; small, slender species ....... M. pygmaea

\section{ACKNOWLEDGEMENTS}

We acknowledge: the staff of the Shoals of Capricorn programme, including Martin Callow, Jan Robinson and Caroline Lawton, for their logistical help in the Seychelles; John Collie and the staff at the Seychelles Marine Parks Authority (MPA) for use of their facilities; the Seychelles Fisheries Authority, especially Captain Gerrard Ernesta and the crew of the R.V. L'Amitie for their expertise and enthusiasm in collecting the offshore samples; BioSyB staff for help in collecting and sorting samples; Andy Woolmer (University of Wales, Swansea, now at SWSFC) and Mairi Best (University of Chicago) for assistance on L'Amitié; Jon Houghton (University of Wales, Swansea) for feeding us all; and the National Museum of Wales for funding the expedition. Many thanks to Charatsee Aungtonya (Phuket Marine Biological Center) for the loan of material from Thailand.

\section{REFERENCES}

Aguado, M.T. and G. San Martín. - 2003. A new species of Magelona Müller, 1858 (Polychaete: Magelonidae). Proc. biol. Soc. Wash., 116: 542-547.

Aguirrezabalaga, F., Ceberio, A. and D. Fiege. - 2001. Octomagelona bizkaiensis (Polychaete: Magelonidae) a new genus and species from the Capbreton Canyon (Bay of Biscay, north-east Atlantic). J. mar. biol. Ass. U.K., 81: 221-224.

Al-Hakin, I. and C.J. Glasby. - 2004. Polychaeta (Annelida) of the Natuna Islands, South China Sea. Raffles Bull.Zool., Suppl. 11: 25-43.

Amoureux, L. - 1983. Annélides polychètes du golfe d'Aqaba (mer Rouge). Description d'un genre nouveau et de deux espèces nouvelles. Bull. Mus. natn. Hist. nat., Paris, Sér. 4, 5(3A): 723-742.

Bolívar, G. A. and P.C. Lana. - 1986. Magelonidae (Annelida: Polychaeta) do litoral sudeste do Brasil. Neritica, 1: 131-147.

Buzhinskaja, G.N. - 1985. Polychaeta of the shelf off south 
Sakhalin and their ecology [In Russian]. Issled. Fauny Morei, 30: $72-224$.

Carrington, B. - 1865. On the chaetopod annelides of the Southport sands. Proc. lit. phil. Soc. Manchr, 4: 176-188.

Cunningham, J.T. and G. A. Ramage. - 1888. The Polychaeta sedentaria of the Firth of Forth. Trans. R. Soc. Edinb., 33: 635684.

Day, J.H. - 1961. The polychaet fauna of South Africa. Part 6 . Sedentary species dredged off Cape coasts with a few new records from the shore. J. Linn. Soc., Zool., 44: 463-560.

Ehlers, E. - 1908. Die bodensässigen Anneliden aus dem Sammlungen der deutschen Tiefsee-Expedition. Wiss. Ergebn. dt. Tiefsee-Exped. "Valdivia", 16: 1-167.

Eliason, A. - 1962. Undersökningar över Öresund. XXXXI. Weitere Untersuchungen über die Polychaetenfauna des Öresunds. Acta Univ. lund., Avd. 2, 58(9): 1-98.

Fauvel, P. - 1953. The Fauna of India including Pakistan, Ceylon, Burma and Malaya. Annelida Polychaeta. The Indian Press, Allahabad.

Fiege, D., F. Licher and A. S. Y. Mackie. - 2000. A partial review of the European Magelonidae (Annelida: Polychaeta): Magelona mirabilis redefined and M.johnstoni sp. nov. distinguished. J. mar. biol. Ass. U.K., 80: 215-234.

Gallardo, V.A. - 1968. Polychaeta from the Bay of Nha Trang, South Viet Nam. Naga Rep., 4(3): 35-279.

Gravier, C. - 1906. Contribution a l'étude des annélides polychètes de la Mer Rouge. Nouv. Archs Mus. Hist. nat., Paris, Sér. 4, 8: 124-236, pl. 1-9.

Harmelin, J.G. - 1964. Étude de l'endofaune des "mattes" d'herbiers de Posidonia oceanica Delile. Recl Trav. Stn mar. Endoume, 35(51): 43-105.

Hartman, O. - 1944. Polychaetous annelids from California, including two new genera and nine new species. Allan Hancock Pacif. Exped., 10: 239-304.

Hartman, O. - 1965. Deep-water benthic polychaetous annelids off New England to Bermuda and other North Atlantic areas. Occ. Pap. Allan Hancock Fdn, 28: 1-378.

Hernández-Alcántara, P. and V. Solís-Weiss. - 2000. Magelonidae from the Mexican Pacific and northern Gulf of Mexico, with the description of a new genus (Meridithia) and four new species. In: D.J. Reish and P. Lana (eds), Proceedings of the 6th International Polychaete Conference, Curitiba, Brazil, 1998. Bull. mar. Sci. 67: 625-644.

Hylleberg, J. and A. Nateewathana. - 1991. Temporal and spatial distribution of subtidal magelonid polychaetes at Phuket Island, Thailand, Andaman Sea. In: M.E. Petersen and J.B. Kirkegaard (eds), Systematics, biology and morphology of world Polychaeta. Proceedings of the 2nd International Polychaete Conference, Copenhagen, 1986. Ophelia, Suppl. 5: 573-578.

Johnson, H. - 1901. The Polychaeta of the Puget Sound region. Proc. Boston Soc. nat. Hist. 29: 381-437.

Johnston, G. - 1865. A catalogue of the British non-parasitical worms in the collection of the British Museum. Trustees of the British Museum, London.

Jones, M.L. - 1963. Four new species of Magelona (Annelida, Polychaeta) and a redescription of Magelona longicornis Johnson. Am. Mus. Novit., 2164: 1-31.

Jones, M.L. - 1968. On the morphology, feeding and behavior of Magelona sp. Biol. Bull., 134: 272-297.

Jones, M.L. - 1971. Magelona berkeleyi n.sp. from Puget Sound (Annelida: Polychaeta) with a further redescription of Magelona longicornis Johnson and a consideration of recently described species of Magelona. J. Fish. Res. Bd Can., 28: 1445-1454.

Jones, M.L. - 1978. Three new species of Magelona (Annelida, Polychaeta) and a redescription of Magelona pitelkai Hartman. Proc. biol. Soc. Wash., 91: 336-363.
Kitamori, R. - 1967. Magelonidae (Polychaetous annelids) from Japan, including the description of a new species. Bull. Tokai reg. Fish. Res. Lab., 50: 49-54.

Mackie, A.S.Y. and P.G. Oliver. - 1996. Marine macrofauna: polychaetes, molluscs and crustaceans. In: G.S. Hall (ed.), Methods for the examination of organismal diversity in soils and sediments, pp. 263-284. CAB International, Wallingford.

Mackie, A.S.Y., Oliver, P.G., Darbyshire, T. and K. Mortimer. 2005. Shallow marine benthic invertebrates of the Seychelles plateau: high diversity in a tropical oligotrophic environment. Phil.Trans. R. Soc., Ser. A, 363: 203-228.

McIntosh, W.C. - 1878. Beiträge zur anatomie von Magelona. Z. wiss. Zool, , 31, 401-472.

McIntosh, W.C. - 1911. On the structures of Magelona. Ann. Mag. nat. Hist., Ser. 8, 7, 417-457.

Mohammad, M.-B.M. - 1970. On two new polychaetous annelids from Kuwait. Zool. Anz., 185: 303-307.

Mohammad, M.-B.M. - 1973. New species and records of polychaete annelids from Kuwait, Arabian Gulf. Zool.J. linn. Soc., 52: $23-44$.

Monro, C.C.A. - 1933. The Polychaeta Sedentaria collected by Dr. C. Crossland at Colón, in the Panama region, and the Galagagos Islands during the expedition of the S.Y. 'St. George'. Proc. zool. Soc. Lond., 1933(4): 1039-1092.

Mortimer, K. and A.S.Y. Mackie. - 2003. The Magelonidae (Annelida: Polychaeta) from the Seychelles, with the description of three new species. In: E. Sigvaldadóttir, A.S.Y. Mackie, G.V. Helgason, D.J. Reish, J. Svavarsson, S.A. Steingrimsson and G. Gudmundsson (eds), Advances in Polychaete Research. Proceedings of the 7th International Polychaete Conference, Reykjavik, Iceland 2001. Hydrobiologia, 496: 163-173.

Moore, J.P. - 1907. Descriptions of new species of spioniform annelids. Proc. Acad. nat. Sci. Philad., 59: 195-207.

Müller, F. - 1858. Einiges über die Annelidenfauna der Insel Santa Catharina au der brasilianischen Küste. Arch. Naturgesch., 24: 211-220.

Nateewathana, A. and J. Hylleberg. - 1991. Magelonid polychaetes from Thailand, the Andaman Sea, with descriptions of eight new species. In: M.E. Petersen and J.B. Kirkegaard (eds), Systematics, biology and morphology of world Polychaeta. Proceedings of the 2nd International Polychaete Conference, Copenhagen, 1986. Ophelia, Suppl. 5: 169-184.

Okuda, S. - 1937. Spioniform polychaetes from Japan. J. Fac. Sci. Hokkaido Univ. Ser. 6 (Zool.) 5: 217-254.

Sveshnikov, V.A. - 1963. Rostraria - the larva of Notopygos sp. (Amphinomidae, Polychaeta) in the South China Sea [In Russian]. Dokl. Akad. Nauk SSSR, 149: 738-741.

Uebelacker, J.M. and M.L. Jones. - 1984. Family Magelonidae. In: J.M. Uebelacker and P.G. Johnson (eds), Taxonomic guide to the polychaetes of the northern Gulf of Mexico, pp. 7.1-7.29. Final report to the Minerals Management Service, contract 1412-001-29091. Barry A. Vittor and Associates, Mobile, Alabama.

Wesenberg-Lund, E. - 1949. Polychaetes of the Iranian Gulf. Dan. Scient. Invest. Iran, 4: 247-400.

Wilson, J.G., A.S.Y. Mackie, B.D.S. O'Connor, E.I.S. Rees and T. Darbyshire. - 2001. Benthic biodiversity in the southern Irish Sea 2. The South-West Irish Sea Survey. Studies in Marine Biodiversity and Systematics from the National Museum of Wales. BIOMÔR Rep. 2(1): 143 pp.

Wilson, D.P. - 1958. The polychaete Magelona alleni $\mathrm{n}$. sp. and a re-assessment of Magelona cincta Ehlers. J. mar. biol. Ass. U.K., 37: 617-626.

Received September 15, 2004. Accepted May 11, 2005. 